\title{
5-Aminosalicylic acid prevents oxidant mediated damage of glyceraldehyde-3-phosphate dehydrogenase in colon epithelial cells
}

\author{
S M McKenzie, W F Doe, G D Buffinton
}

\begin{abstract}
Background-Reactive oxygen and nitrogen derived species produced by activated neutrophils have been implicated in the damage of mucosal proteins including the inhibition of glyceraldehyde-3-phosphate dehydrogenase (GAPDH) in the active inflammatory lesion in patients with inflammatory bowel disease (IBD). This study investigated the efficacy of currently used IBD therapeutics to prevent injury mediated by reactive oxygen and nitrogen derived species.
\end{abstract}

Methods-GAPDH activity of human colon epithelial cells was used as a sensitive indicator of injury produced by reactive oxygen and nitrogen derived species. HCT 116 cells $\left(10^{6} / \mathrm{ml}\right.$ phosphate buffered saline; $37^{\circ} \mathrm{C}$ ) were incubated in the presence of 5-aminosalicylic acid (5ASA), 6-mercaptopurine, methylprednisolone, or metronidazole before exposure to $\mathrm{H}_{2} \mathrm{O}_{2}, \mathrm{HOCl}$, or $\mathrm{NO}$ in vitro. HCT116 cell GAPDH enzyme activity was determined by standard procedures. Cell free reactions between 5-ASA and $\mathrm{HOCl}$ were analysed by spectrophotometry and fluorimetry to characterise the mechanism of oxidant scavenging.

Results-GAPDH activity of HCT116 cells was inhibited by the oxidants tested: the concentration that produced $50 \%$ inhibition $\left(\mathrm{IC}_{50}\right)$ was 44.5 (2.1) $\mu \mathrm{M}$ for $\mathrm{HOCl}$, 379.8 (21.3) $\mu \mathrm{M}$ for $\mathrm{H}_{2} \mathrm{O}_{2}$, and 685.8 (103.8) $\mu M$ for NO (means (SEM)). 5-ASA was the only therapeutic compound tested to show efficacy $(p<0.05)$ against HOCl mediated inhibition of enzyme activity; however, it was ineffective against $\mathrm{H}_{2} \mathrm{O}_{2}$ and NO mediated inhibition of GAPDH. Methylprednisolone, metronidazole, and the thiol-containing 6-mercaptopurine were ineffective against all oxidants. Studies at ratios of $\mathrm{HOCl}$ :5-ASA achievable in the mucosa showed direct scavenging to be the mechanism of protection of GAPDH activity. Mixing 5-ASA and HOCl before addition to the cells resulted in significantly greater protection of GAPDH activity than when $\mathrm{HOCl}$ was added to cells preincubated with 5-ASA. The addition of 5-ASA after HOC1 exposure did not restore GAPDH activity.

Conclusions-Therapies based on 5-ASA may play a direct role in scavenging the potent neutrophil oxidant $\mathrm{HOCl}$, thereby protecting mucosal GAPDH from oxida- tive inhibition. These findings suggest that strategies for the further development of new HOCl scavenging compounds may be useful in the treatment of IBD.

(Gut 1999;44:180-185)

Keywords: 5-aminosalicylic acid; 6-mercaptopurine; prednisolone; metronidazole; oxidants;

glyceraldehyde-3-phosphate dehydrogenase

Inflammatory bowel disease (IBD) is characterised by a dense inflammatory cell infiltrate mainly comprising neutrophils (PMNs), macrophages, and lymphocytes. Activated PMNs produce potent reactive oxygen and nitrogen derived species capable of causing tissue injury in the active lesion. ${ }^{1}$ Direct evidence of a pathogenic role for these reactive species in IBD is suggested by the finding of oxidised protein thiols in colon epithelial cells from the active lesion. ${ }^{2}$ Other indirect evidence includes the depletion of antioxidants from the inflamed mucosal lesion, ${ }^{3}{ }^{4}$ increased production of oxidants in peripheral blood of patients with IBD, and the efficacy of anti-inflammatory compounds with oxidant scavenger activity in limited clinical trials and in animal models of IBD. ${ }^{5-8}$

Recent research has focused on the role of oxidant scavenging by 5 -aminosalicylic acid (5-ASA) in the treatment of IBD. 5-ASA is able to scavenge hypochlorite $(\mathrm{HOCl}),{ }^{9}$ the most potent oxidant produced by PMNs. 5-ASA also scavenges chloramines, ${ }^{10}$ superoxide anion $^{11}{ }^{12}$ and $\mathrm{OH} .{ }^{12}{ }^{13}$ It also inhibits lipid peroxidation ${ }^{14}$ and protects cultured cells from oxidative damage by activated phagocytes. ${ }^{15}$ Laffafian et $a l^{16}$ have shown that the amine group of 5-ASA is essential to scavenge HOCl. Moreover, the amine group of 5-ASA and 4-aminosalicylic acid is a requirement for therapeutic efficacy in IBD. ${ }^{17}$ Small amounts of oxidised 5-ASA have been identified in the faeces of IBD patients with active disease, ${ }^{18} 19$ strengthening the evidence that 5-ASA may act as a scavenger of oxidants in the intestinal lumen.

Other therapies used currently for IBD may also act as oxidant scavengers. Azathioprine undergoes hepatic cleavage releasing the thiolcontaining 6-mercaptopurine. Inflammatory

Abbreviations used in this paper: IBD,

inflammatory bowel disease; PMN, neutrophil; 5-ASA, 5-aminosalicylic acid; GAPDH,

glyceraldehyde-3-phosphate dehydrogenase; HBSS, Hanks balanced salt solution; $\mathrm{IC}_{50}$, concentration that produces $50 \%$ inhibition. 


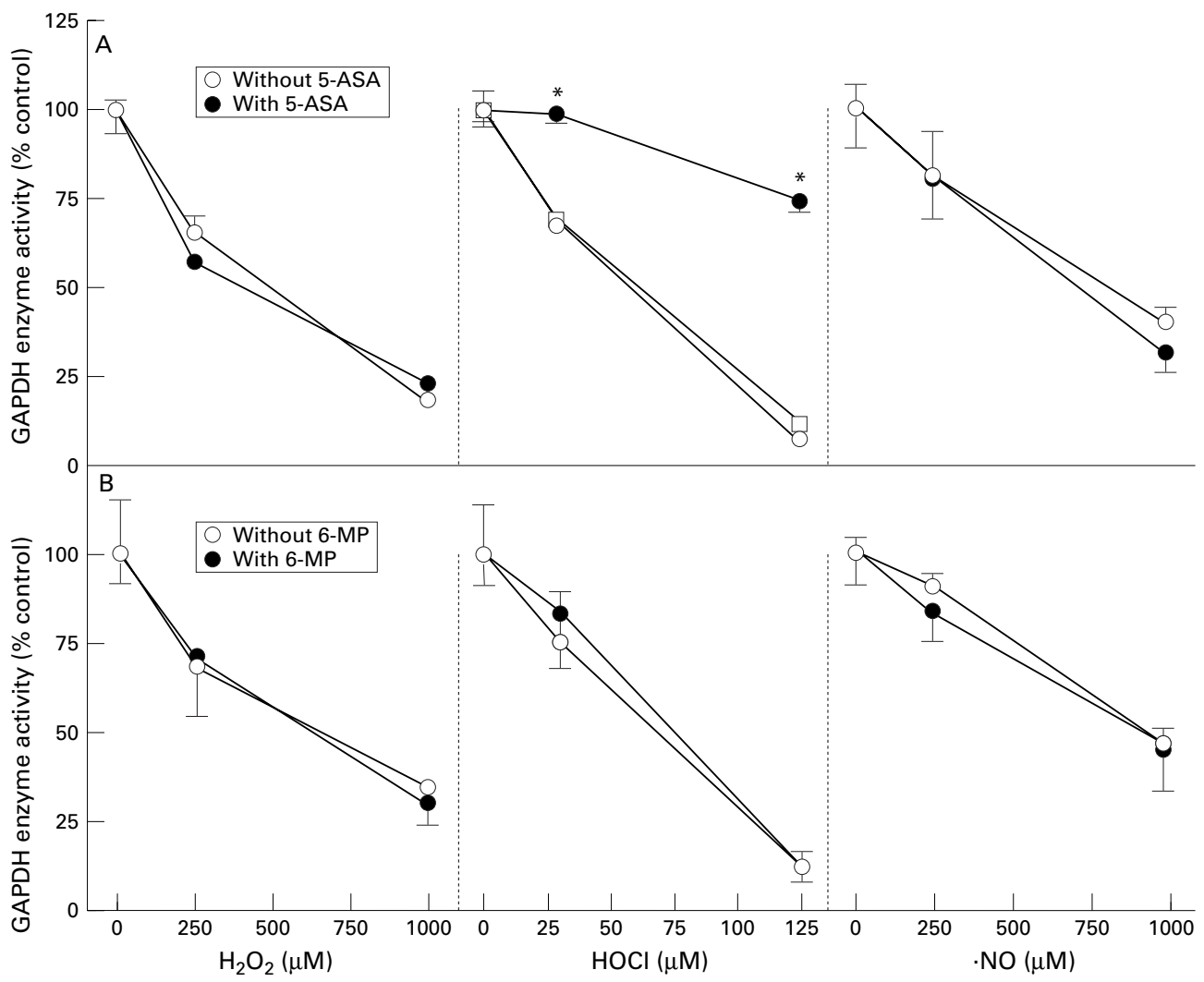

Figure 1 Efficacy of 5-aminosalicylic acid (5-ASA) and 6-mercaptopurine (6-MP) against oxidant mediated inhibition of glyceraldehyde-3-phosphate dehydrogenase (GAPDH) activity. $\mathrm{HCT116}$ cells were exposed to $\mathrm{H}_{2} \mathrm{O}_{2}, \mathrm{HOCl}$, or $\mathrm{NO}$ after preincubation $(A)$ in the absence or presence of 5-ASA or incubated with 5-ASA after exposure to HOCl or (B) in the absence or presence of 6-mercaptopurine. Oxidant and therapeutic concentrations were as described in the Materials and methods section. Data represent mean (SEM) $(n=3)$. ${ }^{\star} p<0.05$ compared with no 5-ASA.

oxidants such as $\mathrm{HOCl}$, chloramines, $\mathrm{NO}$, and $\mathrm{H}_{2} \mathrm{O}_{2}$ react rapidly with thiols and may also contribute to the decrease in GSH levels found in the inflamed mucosa of IBD patients ${ }^{420}$ and in dextran sodium sulphate induced colitis in mice. ${ }^{21}$ The thiol group in 6-mercaptopurine may also offer protection against cellular oxidative injury by providing an alternative thiol target for inflammatory oxidants.

Oxidation of the active site thiol of the glycolytic enzyme glyceraldehyde-3-phosphate dehydrogenase (GAPDH) and subsequent inhibition of enzyme activity were consistent findings in colon epithelial cells purified from the inflamed mucosa of IBD patients, providing a marker of intracellular oxidative injury. ${ }^{2}$ In this paper we compare the efficacy of a range of currently used IBD therapeutic compounds (5-ASA, 6-mercaptopurine, methylprednisolone, and metronidazole) in the prevention of GAPDH inhibition caused by in vitro exposure to $\mathrm{HOCl}, \mathrm{NO}$, or $\mathrm{H}_{2} \mathrm{O}_{2}$.

\section{Materials and methods}

TREATMENT OF HCT116 CELLS WITH THERAPEUTIC COMPOUNDS

HCT 116 cells were maintained in RPMI 1640 containing $10 \%$ fetal calf serum. Cell suspensions were washed into Hanks balanced salt solution (HBSS), $\mathrm{pH} 7.4$, without phenol red or glucose and preincubated in a shaking water bath for 30 minutes at $37^{\circ} \mathrm{C}$ with 5-ASA (Fluka Chemie, Buchs, Switzerland), 6-mercapto- purine (Sigma, St Louis, Missouri, USA), methylprednisolone (Solu-Medrol; Upjohn Pty Ltd, Rydalmere, NSW, Australia), or metronidazole (Flagyl; May and Baker Pty Ltd, Sydney, NSW, Australia). The therapeutic compounds were added at a final concentration of $250 \mu \mathrm{M}$ for the $\mathrm{HOCl}$ treated samples and at $2 \mathrm{mM}$ for the $\mathrm{H}_{2} \mathrm{O}_{2}$ and $\mathrm{NO}$ treated samples such that the final molarity of the therapeutic compound was twice the maximum concentration of oxidant to be used.

Cell preparations were then exposed to various concentrations of $\mathrm{HOCl}$ (Merck, Melbourne, Vic, Australia), $\mathrm{H}_{2} \mathrm{O}_{2}$ (BDH Chemicals, Melbourne, Vic, Australia), or NO (diethylamine NONOate; Cayman Chemical Company, Ann Arbor, Michigan, USA). Stock

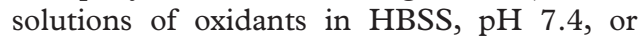
phosphate buffered saline, $\mathrm{pH} 8.5$, for diethamine NONOate, were added to $2 \mathrm{ml}$ cell preparations in $100 \mu \mathrm{l}$ aliquots. Final concentrations were $0,31.25$, and $125 \mu \mathrm{M} \mathrm{HOCl}$ and 0,250 , and $1000 \mu \mathrm{M}$ for $\mathrm{H}_{2} \mathrm{O}_{2}$ and $\mathrm{NO}$ respectively. The range of oxidant concentrations was selected to produce about $20-90 \%$ inhibition of GAPDH enzyme activity. After the 30 minute incubation, cell preparations were washed twice in HBSS to remove unreacted oxidant and therapeutic compound, resuspended in $100 \mathrm{mM}$ Tris/ $\mathrm{HCl}$ with $0.5 \mathrm{mM}$ EDTA, and assayed for GAPDH. ${ }^{2}$ Cell viability, assessed by trypan blue exclusion after 


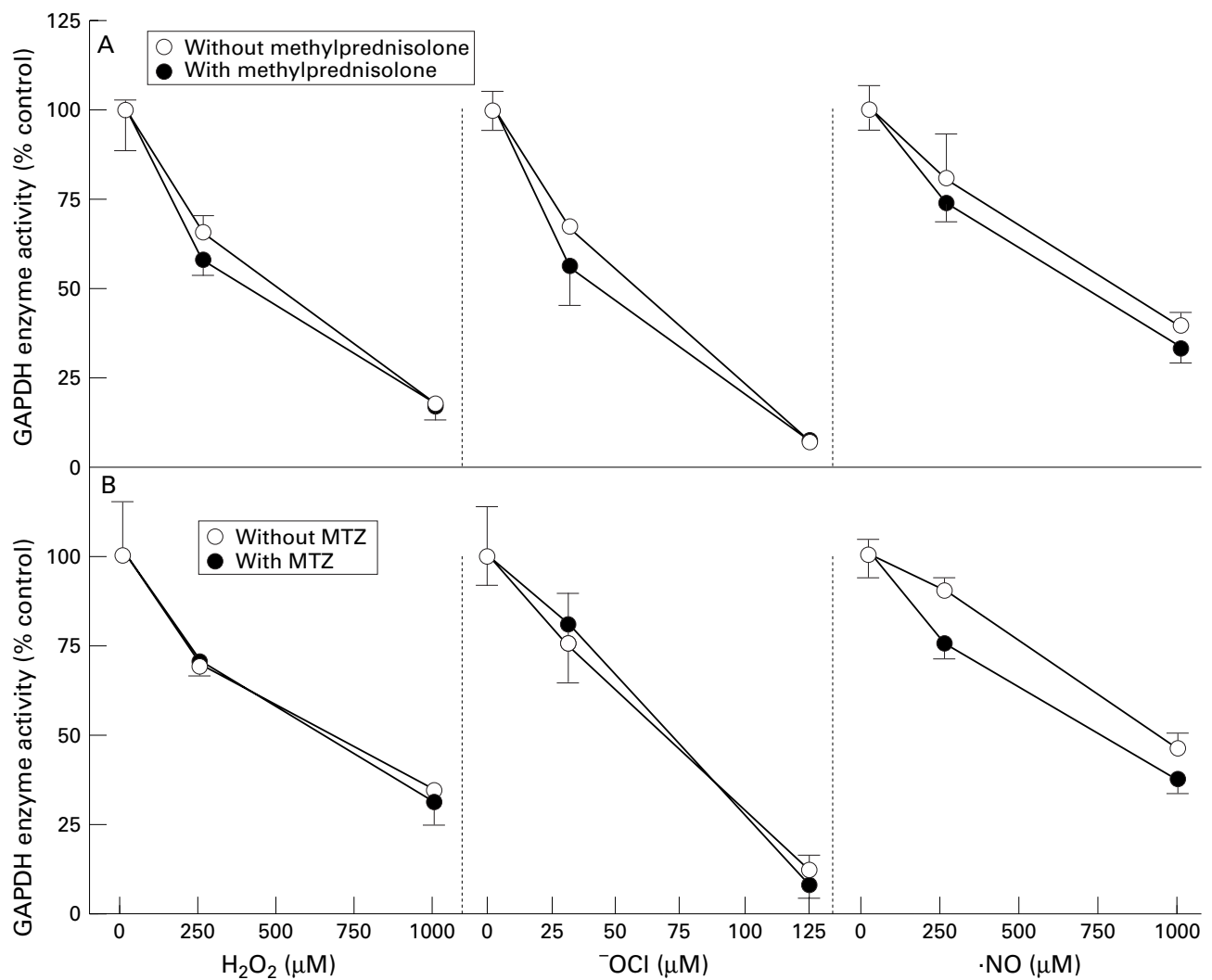

Figure 2 Efficacy of methylprednisolone and metronidazole against oxidant mediated inhibition of glyceraldehyde-3-phosphate dehydrogenase (GAPDH) activity. $\mathrm{HCT116}$ cells were exposed to $\mathrm{H}_{2} \mathrm{O}_{2}, \mathrm{HOCl}$, or $\mathrm{NO}$ after preincubation (A) in the absence or presence of methylprednisolone or (B) in the absence or presence of metronidazole (MTZ). Oxidant and therapeutic concentrations were as described in the Materials and methods section. Data represent mean (SEM) $(n=3)$.

treatment by each oxidant or drug combination, was always $95 \%$ or greater.

\section{GAPDH ACTIVITY}

GAPDH activity of cell lysates was determined as described previously ${ }^{22}$ and adapted for use in HCT116 cells. ${ }^{2}$ Cell lysates $(100 \mu \mathrm{l})$ were added to a $1 \mathrm{ml}$ reaction mixture containing 10 $\mathrm{mM} \mathrm{MgCl}, 200 \mu \mathrm{M}$ NADH, $2 \mathrm{mM}$ ATP, $5 \mathrm{U} / 1$ phosphoglycerate kinase in $100 \mathrm{mM}$ Tris/HCl/ EDTA, $\mathrm{pH} 8$, and preincubated at $37^{\circ} \mathrm{C}$ for about 10 minutes. The reaction was initiated by the addition of $10 \mathrm{mM} 3$-phosphoglycerate. Enzyme activity was determined using a Varian

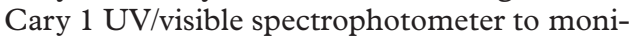
tor the oxidation of $\mathrm{NADH}\left(\varepsilon_{340}=6.22 \times 10^{3}\right.$ $\mathrm{M}^{-1} \mathrm{~cm}^{-1}$ ) by the reverse reaction of GAPDH coupled with phosphoglycerate kinase.

\section{REACTION OF 5-ASA WITH HOCl}

5-ASA $(250 \mu \mathrm{M})$ in HBSS was allowed to react with $\mathrm{HOCl}$ in a cell free system for 15 minutes at $37^{\circ} \mathrm{C}$ with constant agitation using the ratios of $\mathrm{HOCl}: 5$-ASA of $0,0.25,0.5,0.75,1,1.5,2$, 3 , 4, and 5:1. After 15 minutes of incubation, the reaction was stopped by the addition of excess taurine $(6.25 \mathrm{mM}$, five times the maximum $\mathrm{HOCl}$ concentration) to scavenge any unreacted $\mathrm{HOCl}$. The absorbance profiles of the reaction products of 5-ASA and $\mathrm{HOCl}$ were determined by scanning absorbance from 280 to $900 \mathrm{~nm}$ (Varian Cary $1 \mathrm{UV} /$ visible spectrophotometer). The reaction of $\mathrm{HOCl}$ and
5-ASA was stopped after 15 minutes of incubation by the addition of $6.25 \mathrm{mM}$ taurine. There was no significant absorbance between 280 and $900 \mathrm{~nm}$ of either $6.25 \mathrm{mM}$ taurine or a mixture of $6.25 \mathrm{mM}$ taurine and $1.25 \mathrm{mM}$ $\mathrm{HOCl}$ (data not shown). The fluorescence of $250 \mu \mathrm{M}$ 5-ASA in HBSS after the addition of $\mathrm{HOCl}$ (final concentration $250 \mu \mathrm{M}$ ) was continuously monitored for 30 minutes (excitation wavelength $340 \mathrm{~nm}$, emission wavelength $500 \mathrm{~nm}$; Hitachi 3000 fluorimeter, fitted with a magnetic stirrer). To analyse this reaction further, the fluorescence emission scans from 220 to $800 \mathrm{~nm}$ (excitation wavelength $340 \mathrm{~nm}$ ) were determined for the reaction products of 5-ASA and $\mathrm{HOCl}$.

STATISTICAL ANALYSIS

Paired Student's $t$ tests were used to assess the statistical significance of the data. Statistical significance was accepted when $p \leqslant 0.05$.

\section{Results}

EFFICACY OF THERAPEUTIC AGENTS TOWARD

OXIDANT INDUCED INHIBITION OF GAPDH

ACTIVITY

The oxidants $\mathrm{H}_{2} \mathrm{O}_{2}, \mathrm{HOCl}$, and $\mathrm{NO}$ induced concentration dependent inhibition of GAPDH activity, with $\mathrm{HOCl}$ being about 10-fold more effective than $\mathrm{H}_{2} \mathrm{O}_{2}$ and $\mathrm{NO}$ (figs 1 and 2, open circles), consistent with our earlier observations. ${ }^{2}$ The concentrations producing $50 \%$ inhibition of GAPDH $\left(\mathrm{IC}_{50}\right)$ were 


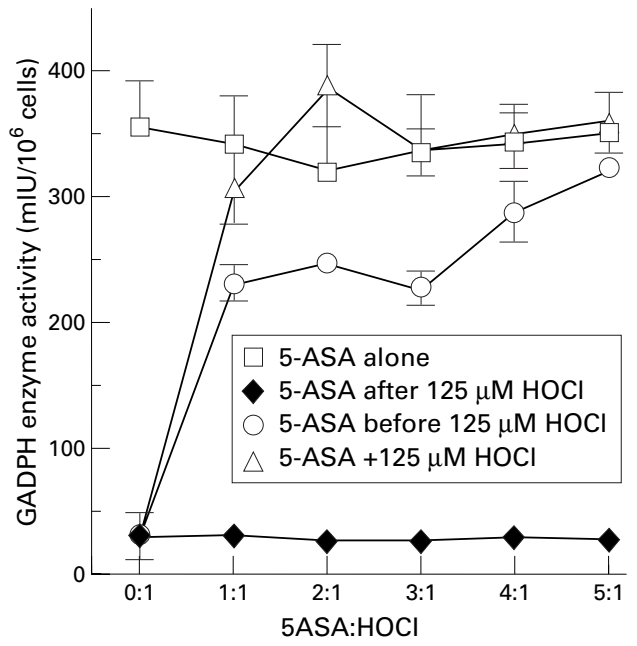

Figure 3 Dose-dependence of 5-aminosalicylic acid (5-ASA) prevention of the inhibition of glyceraldehyde-3-phosphate dehydrogenase (GAPDH) activity mediated by $\mathrm{HOCl}$. HCT116 cells were exposed to increasing ratios of 5- $A S A$ : $\mathrm{HOCl}$ according to the following protocol: 5-ASA alone, 5-ASA after exposure to $125 \mu \mathrm{M} \mathrm{HOCl}, 5-\mathrm{ASA}$ before exposure to $125 \mu \mathrm{M} \mathrm{HOCl}$, or the spent reaction resulting from the premixing of 5-ASA with $125 \mu \mathrm{M}$ HOCl. Data represent mean (SEM) ( $n=$ 3).

44.5 (2.1) $\mu \mathrm{M}$ for $\mathrm{HOCl}, 379.8$ (21.3) $\mu \mathrm{M}$ for $\mathrm{H}_{2} \mathrm{O}_{2}$, and 685.8 (103.8) $\mu \mathrm{M}$ for NO (means $(\mathrm{SEM})$ ). To determine the relative oxidant scavenging capacity of each of the therapies, identical ratios of oxidant:therapy were used.

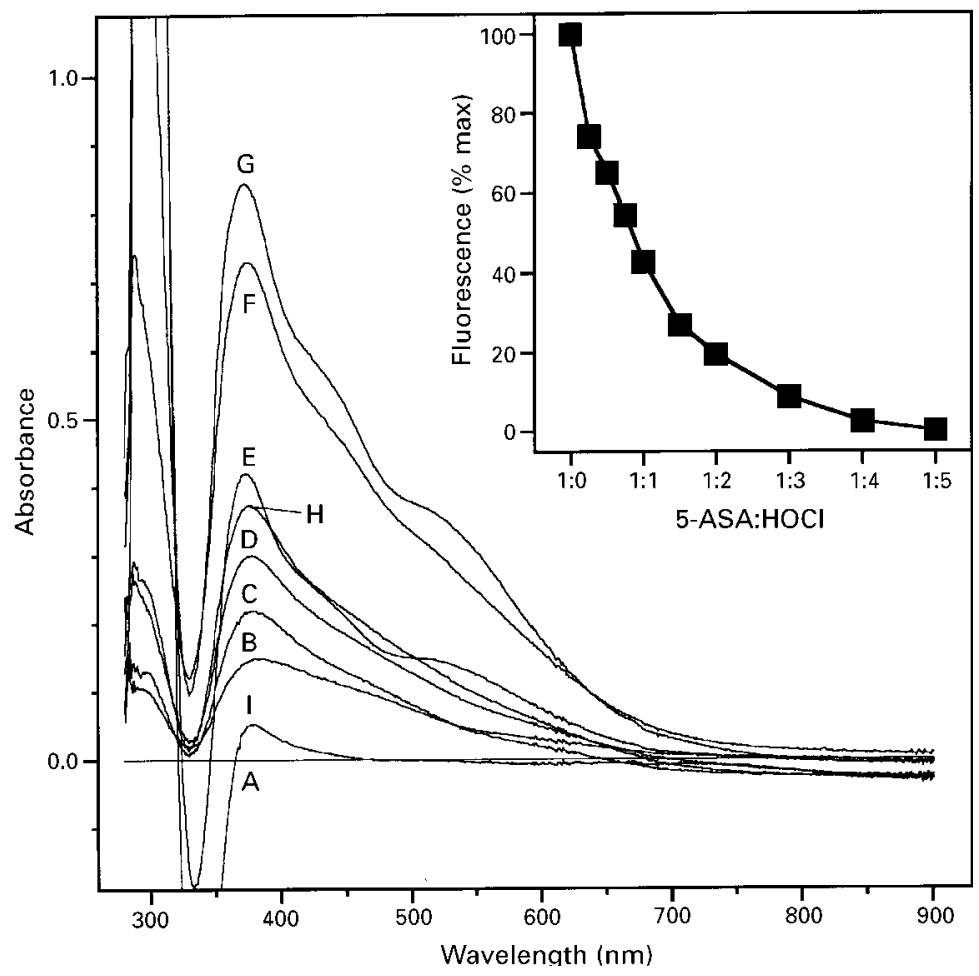

Figure 4 Reaction of 5-aminosalicylic acid (5- $A S A$ ) with $\mathrm{HOCl}$. Increasing concentrations of HOCl were allowed to react with 5-ASA as described in the Materials and methods section and differential absorbance spectrums determined. The reference cuvette contained $250 \mu M$ 5-ASA in HBSS, and the sample cuvette increasing ratios of 5-ASA:HOCl; $37^{\circ} \mathrm{C}$. Absorbance traces of 5-ASA:HOCl were as follows: $\mathrm{A}, 1: 0 ; \mathrm{B}$, $1: 0.25 ; C, 1: 0.5 ; D, 1: 0.75 ; E, 1: 1 ; F, 1: 2 ; G, 1: 3 ; H, 1: 4 ; I, 1: 5$. Insert, 5-ASA fluorescence.
5-ASA AND 6-MERCAPTOPURINE

The presence of low concentrations of 5-ASA protected HCT116 cells against $\mathrm{HOCl}$ induced inhibition of GAPDH activity $(\mathrm{p}<0.05)$, whereas 5-ASA did not prevent inhibition of GAPDH activity by the myeloperoxidase substrate, $\mathrm{H}_{2} \mathrm{O}_{2}$, or the $\mathrm{NO}$ synthase product, $\mathrm{NO}$, at comparable drug:oxidant ratios (fig 1A). The addition of 5-ASA after the addition of $\mathrm{HOCl}$ was also ineffective. At the same drug:oxidant ratios, the exposure of HCT116 cells to oxidants in the presence of the thiol-containing drug 6-mercaptopurine did not result in significant $(p>0.05)$ protection of GAPDH activity, compared with control untreated cells exposed to the same concentrations of oxidant (fig 1B). Accordingly, there was no significant difference in the $\mathrm{IC}_{50}$ value of GAPDH enzyme activity (not shown), except for $5-\mathrm{ASA} / \mathrm{HOCl}$ when the $\mathrm{IC}_{50}$ value increased from $44.5(2.1)$ to $536.8(83.2) \mu M(p<0.05)$.

METHYLPREDNISOLONE AND METRONIDAZOLE

Methylprednisolone and metronidazole added before exposure of HCT 116 cells $\left(10^{6} / \mathrm{ml}\right)$ did not prevent the inhibition of GAPDH activity induced by $\mathrm{HOCl}, \mathrm{NO}$, or $\mathrm{H}_{2} \mathrm{O}_{2}$ (fig 2). Neither compound caused a significant difference in the $\mathrm{IC}_{50}$ values of GAPDH activity (not shown).

CONCENTRATION DEPENDENCE OF 5-ASA PROTECTION OF CELLULAR GAPDH FROM OXIDANT MEDIATED INHIBITION

To investigate the mechanism of GAPDH protection further, HCT116 cells were incubated with increasing ratios of 5-ASA:HOCl. The GAPDH activity of control untreated HCT 116 cells, 353.80 (37.76) mIU/ $10^{6}$ cells, was unaffected by the addition of 5-ASA (fig 3). In the presence of $\mathrm{HOCl}$ alone, only 8.5 (5.1) $\%$ of enzyme activity remained after 30 minutes of exposure. At a 1:1 ratio of 5-ASA:HOCl, 65.1 (4.3)\% of control activity remained and at a ratio of $5: 1$ there was almost $90 \%$ of control GAPDH activity (fig 3). If 5-ASA was added after $\mathrm{HOCl}$, however, no protection against $\mathrm{HOCl}$ induced inhibition of GAPDH activity was observed, showing that the mechanism probably involves scavenging rather than regeneration of the inhibited enzyme. When 5-ASA and $\mathrm{HOCl}$ were incubated together in $\mathrm{HBSS}$ for 30 minutes at $37^{\circ} \mathrm{C}$ before the addition of the spent reaction mixture to HCT116 cells, considerable protection of GAPDH activity (86.0 7.8)\%) was observed at a 5-ASA:HOCl ratio of 1:1. At higher 5-ASA: $\mathrm{HOCl}$ ratios, the GAPDH activity was indistinguishable from that of controls (fig 3).

REACTION OF 5-ASA WITH HOCl

In a cell free system, reaction of 5-ASA: $\mathrm{HOCl}$ ratios up to $1: 1$ caused no change to the maximum 5-ASA UV-visible absorbance at $330 \mathrm{~nm}$. There was, however, an $\mathrm{HOCl}$ dependent increase in absorbance between 350 and 650 $\mathrm{nm}$ that resulted in a yellow-brown reaction product, with the greatest increase at $375 \mathrm{~nm}$ which intensified up to a ratio of 1:3 (fig 4). 
Analysis of 5-ASA fluorescence spectra at the same 5-ASA: $\mathrm{HOCl}$ ratios showed that 5-ASA was consumed (fluorescence decay) rapidly on the addition of $\mathrm{HOCl}$ (not shown), consistent with a previous report. ${ }^{9}$ Coincident with the maximum formation of the yellow-brown reaction product was near complete loss of fluorescence after reaction of 1:3 5-ASA: $\mathrm{HOCl}$ (fig 4, insert). The marked decrease in absorption characteristics at $>3: 1 \mathrm{HOCl}$ :5-ASA ratios indicates that each molecule of 5-ASA is able to scavenge/interact with at least three molecules of $\mathrm{HOCl}$ before losing potency and apparently undergoing decomposition reactions (fig 4, traces $\mathrm{H}$ and $\mathrm{I}$ ). $\mathrm{HOCl}$ is also able to mediate the decomposition of the structurally similar salicylate and its hydroxylated derivatives with loss of fluorescence. ${ }^{23}$

\section{Discussion}

5-ASA, the active principle in many standard therapies used in the treatment of IBD, was found to be an effective scavenger of $\mathrm{HOCl}$ and prevented oxidation and inhibition of GAPDH in colon epithelial HCT116 cells. Little scavenging effect was observed, however, with the relatively weaker oxidants, $\mathrm{NO}$ and $\mathrm{H}_{2} \mathrm{O}_{2}$. The other therapeutic compounds used in IBD, methylprednisolone, metronidazole, and the thiol-containing 6-mercaptopurine, when used at clinically relevant concentrations, did not protect GAPDH activity in HCT116 cells exposed to the oxidants $\mathrm{HOCl}, \mathrm{NO}$, and $\mathrm{H}_{2} \mathrm{O}_{2}$. The mechanism by which 5-ASA protects appears to involve a direct reaction between 5-ASA and $\mathrm{HOCl}$, as 5-ASA added after $\mathrm{HOCl}$ treatment of cells was unable to reverse GAPDH inhibition. Furthermore, premixing of 5-ASA and $\mathrm{HOCl}$ before their addition to colon epithelial cells quenched the capacity of $\mathrm{HOCl}$ to injure GAPDH.

The central role of PMNs in mucosal injury stems from the characteristic extravasation and infiltration of large numbers of cells into the mucosa. Contempary studies using PMN depletion strategies ${ }^{24}$ and a deeper understanding of the role cytokines play in the recruitment of inflammatory cells from the peripheral circulation ${ }^{25}{ }^{26}$ confirm this role in tissue injury in the active lesion. PMNs possess a variety of mechanisms capable of initating such injury including the generation of potent oxidants such as $\mathrm{HOCl} .{ }^{1}$ We have reported recently that the glycolytic enzyme GAPDH became oxidized and lost activity in the inflamed mucosa of patients with IBD, a result that could be mimicked by exposing cells to oxidants in vitro. ${ }^{2}$ While we were unable to source the oxidant(s) responsible for this oxidation in vivo, the efficacy of $\mathrm{HOCl}$ compared with other oxidants, the irreversible nature of the oxidation, ${ }^{27}$ and the pattern of protein thiol oxidation in patient samples was representative of $\mathrm{HOCl} /$ chloramine rather than $\mathrm{H}_{2} \mathrm{O}_{2} / \mathrm{NO}$. In animal models of inflammation, inflamed tissue contains upwards of $10^{7} \mathrm{PMNs} / \mathrm{g}$ tissue, sufficient to yield about $0.6 \mathrm{mM} \mathrm{HOCl} / \mathrm{h}^{28}$ While defences against $\mathrm{O}_{2}^{-} \cdot / \mathrm{H}_{2} \mathrm{O}_{2}$ and the hydroxyl radical $(\cdot \mathrm{OH})$ are part of normal homoeostasis with regeneration of GSH and membrane anti- oxidants by metabolic reducing equivalents, the primary defence against $\mathrm{HOCl}$ would involve irreversible reaction with and depletion of GSH and protein thiols. The inability to readily regenerate thiols oxidised by $\mathrm{HOCl}$ would compromise other cellular defences to $\mathrm{O}_{2}^{-\cdot} / \mathrm{H}_{2} \mathrm{O}_{2}$ or $\cdot \mathrm{OH}$ for example, an end result that appears to be present in the actively inflamed mucosa of IBD patients ${ }^{3}{ }^{4}$ and in mice with dextran sulphate induced colitis. ${ }^{21}$

The mechanisms of action of 5-ASA in the inflamed mucosa in vivo have been difficult to elucidate because 5-ASA inhibits multiple inflammatory processes in vitro ranging from the inhibition of cyclo-oxygenase and lipoxygenase pathways to scavenging of inflammatory cell derived oxidants. ${ }^{29}$ While the inhibitory activities of 5-ASA were observed at high concentrations $(6-10 \mathrm{mM})$, the mucosal concentrations of $5-\mathrm{ASA}^{30}$ were found to be very much lower $(5-400 \mu \mathrm{M})$, comparable with the $\mathrm{IC}_{50}$ for the efficacy of 5-ASA scavenging of oxidants, supporting the scavenging mechanism. ${ }^{29}$ Scavenging of $\mathrm{HOCl}$ was observed here at 5-ASA: $\mathrm{HOCl}$ ratios expected in vivo and comparable with those that provided protection of essential thiols on $\alpha_{1}$-antiprotease inhibitor $^{13}$ and cysteine ${ }^{10}$ from oxidation by $\mathrm{HOCl}$. HOCl reacts initially with the amino group of 5-ASA to form a short lived chloramine that appeared to spontaneously decompose to 5-nitrososalicylic acid and other species. ${ }^{16}$ The formation of a short lived chloramine intermediate may limit oxidative injury, as in previous in vitro studies, we have shown that chloramine $\mathrm{T}$ was $8-10$-fold less reactive than $\mathrm{HOCl}$ in mediating oxidative inhibition of colon epithelial cell GAPDH. ${ }^{2}$ $\mathrm{HOCl}$ mediated oxidation of 5-ASA produced a golden-brown reaction product of 5-ASA which was identified as a trimeric species of 5-ASA. ${ }^{18} 31$ While other products have been proposed such as 2,5-dihydroxybenzoate and salicylate, ${ }^{15}$ their formation has not been substantiated.

5-ASA has been shown to possess potent antioxidant capacity toward the radical and non-radical forms of ferryl haemoglobin $\left(\mathrm{Hb}_{\mathrm{IV}}\right)$ generated by the reaction of $\mathrm{H}_{2} \mathrm{O}_{2}$ with $\mathrm{Hb}_{\text {III }}$ and inhibition of $\mathrm{Hb}_{\mathrm{IV}}$ mediated lipid peroxidation. ${ }^{14}$ The electron donation from 5-ASA to the haem moiety would have formed a redox couple with continuous reduction of $\mathrm{Hb}_{\text {IV }}$ to $\mathrm{Hb}_{\text {III }}$, similar to a "peroxidase"-like reaction as for the ferryl myoglobin $\left(\mathrm{H}_{2} \mathrm{O}_{2}+\right.$ $\mathrm{Mb}_{\mathrm{III}}$ /ascorbate, ${ }^{32}$ glutathione ${ }^{33}$ or $\mathrm{Mb}_{\mathrm{IV}}-1,4-$ naphthoquinone-glutathionyl conjugates. ${ }^{34} 35$ This mechanism could serve as an important sink for $\mathrm{H}_{2} \mathrm{O}_{2}$ in the inflamed IBD mucosa which has compromised antioxidant defences including decreased total radical scavenging capacity, reduced and total ascorbate, reduced glutathione, urate and ubiquinol-10 compared with paired non-inflamed mucosa. ${ }^{34}$ This deficit is compounded by the significantly lower activities of catalase, glutathione peroxidase, and superoxide dismutase found in the colonic mucosa compared with hepatic activities. ${ }^{36}$ The scavenging activity of 5-ASA has also been extended to the inhibition of myeloperoxidase. 
Direct alternative substrate substitution of the aminosalicylate with decomposition of the myeloperoxidase compound I protein free radical species has been shown to prevent oxidation of chloride anions and formation of $\mathrm{HOCl}^{37}$ Thus 5-ASA may scavenge $\mathrm{HOCl}$ directly or indirectly, thereby protecting colon epithelial and lamina propria cells from injury.

The role of NO in causing tissue injury in the inflamed IBD mucosa remains unclear. Certainly, the evidence that NO, and peroxynitrate, are reactive toward thiols including GAPDH, the immunohistochemical evidence of increased expression of inducible $\mathrm{NO}$ synthase, and the detection of nitrotyrosine in inflamed lesions is compelling. However, the variable efficacy of inducible NO synthase inhibitors as anti-inflammatory agents and our observation $^{27}$ that in vivo oxidation of GAPDH in IBD patients resembles in vitro oxidation by $\mathrm{HOCl}$ or a chloramine and appears distinct from oxidation by either $\mathrm{NO}$ or $\mathrm{H}_{2} \mathrm{O}_{2}$ challenges the acceptance of the role of NO in tissue injury. While 5-ASA failed to prevent the loss of GAPDH activity caused by $\mathrm{NO}$, it can protect against $\mathrm{NO}$ oxidation of an aromatic amine in a cell free system. ${ }^{38}$ However, when the amino group is in the 4 position as in 4-ASA, little NO scavenging was observed. Taken together, these findings suggest that, while considerable evidence implicates $\mathrm{NO}$ in the pathogenesis of mucosal inflammation in IBD, the scavenging of NO does not appear to be a significant mode of action of 5-ASA.

The results presented here show clearly that 5-ASA scavenges $\mathrm{HOCl}$ and is able to prevent GAPDH oxidation and inhibition in a cellular system at 5-ASA:HOCl ratios achievable in vivo. This supports the case for developing new $\mathrm{HOCl}$ scavenging compounds directed at conditions involving $\mathrm{HOCl}$ mediated injury such as IBD and complement existing therapies used to modulate immune responsiveness.

G D B ackowledges the support of NHMRC Australia.

1 Babbs CF. Oxygen radicals in ulcerative colitis. Free Radic Biol Med 1992;13:169-81.

2 McKenzie SJ, Baker MS, Buffinton GD, et al. Evidence of oxidant-induced injury to epithelial cells during inflammatory bowel disease. $\mathcal{F}$ Clin Invest 1996;98:136-41.

3 Buffinton GD, Doe WF. Altered ascorbic acid status in the mucosa from inflammatory bowel disease patients. Free Radic Res 1995;22:131-43.

4 Buffinton GD, Doe WF. Depleted mucosal antioxidant defences in inflammatory bowel disease. Free Radic Biol Med 1995;19:911-918.

5 Emerit J, Pelletier S, Likforman J, et al. Phase II trial of copper zinc superoxide dismutase (CuZn SOD) in treatment of Crohn's disease. Free Radic Res Commun 1991;12-13: 563-9.

6 Niwa Y, Somiya K, Michelson AM, et al. Effect of liposomal-encapsulated superoxide dismutase on active liposomal-encapsulated superoxide dismutase on active
oxygen-related human disorders. A preliminary study. Free oxygen-related human disorders. A
Radic Res Commun 1985;1:137-53.

7 von Ritter C, Grisham MB, Hollwarth M, et al. Neutrophilderived oxidants mediate formyl-methionyl-leucylphenylalanine-induced increases in mucosal permeability in rats. Gastroenterology 1989;97:778-80.

8 Keshavarzian A, Morgan G, Sedghi S, et al. Role of reactive oxygen metabolites in experimental colitis. Gut 1990;31: $786-90$.

9 Williams JG, Hallett MB. The reaction of 5-aminosalicylic acid with hypochlorite. Implications for its mode of action in inflammatory bowel disease. Biochem Pharmacol 1989; 38:149-54.

10 Tamai H, Kachur JF, Grisham MB, et al. Scaverging effect of 5-aminosalicylic acid on neutrohil-derived oxidants: possible contribution to the mechanism of action in inflammatory bowel disease. Biochem Pharmacol 1991;41:1001-6.
11 Carlin G, Djursater R, Smedegard G, et al. Effect of anti-inflammatory drugs on xanthine oxidase and xanthine xidase induced depolymerization of hyaluronic acid. Agents Actions 1985;16:377-84.

12 Miyachi Y, Yoshioka A, Imamura S, et al. Effect of sulphasalazine and its metabolites on the generation of reactive oxygen species. Gut 1987;28:190-5.

13 Aruoma OI, Wasil M, Halliwell B, et al. The scavenging of oxidants by sulphasalazine and its metabolites. A possible contribution to their anti-inflammatory effects? Biochem Pharmacol 1987;36:3739-42.

14 Yamada T, Volkmer C, Grisham MB. The effects of sulfasalazine metabolites on hemoglobin-catalyzed lipid peroxidation. Free Radic Biol Med 1991;10:41-9.

15 Dull BJ, Salata K, Van Langenhove A, et al. 5-Aminosalicylate: oxidation by activated leukocytes and protection of cultured cells from oxidative damage. Biochem protection of cultured cells from

16 Laffafian I, Brown RC, Hallett MB. The production of an amine-modified derivative of 5-aminosalicylic acid by actiated neutrophils. Roles for myeloperoxidase and chloride ions. Biochem Pharmacol 1991;42:1869-74.

17 Campieri M, Lanfranchi GA, Bertoni F, et al. A doubleblind clinical trial to compare the effects of 4-aminosalicylic acid to 5-aminosalicylic acid in topical treatment of ulcerative colitis. Digestion 1984;29:204-8.

18 Jensen J, Cornett C, Olsen CE, et al. Identification of oxidation products of 5 -aminosalicylic acid in faeces and the study of their

19 Ahnfelt-Rønne I, Nielsen OH, Chrisensin A, et al. Clinical evidence supporting the radical scavenger mechanism of 5-aminosalicylic acid. Gastroenterology 1990;98:1162-9.

20 Lauterburg BH, Bilzer M, Rowedder E, et al. Decreased glutathione in inflamed colonic mucosa in man. Possible role of hypochlorous acid and prevention by role of hypochlorous acid and prevention by tory bowel disease: current status and future approach. tory bowel disease: current status and future approach
Amsterdam: Elsevier Science Publishers, 1988:273-6.

21 Blackburn AC, Buffinton GD, Doe WF. Colonic antioxidant status in dextran sulfate-induced colitis in mice. Inflammatory Bowel Disease 1997;3:198-203.

22 Beutler E. Glyceraldehyde phosphate dehydrogenase (GAPDH). In: Red cell metabolism: a manual of biochemical methods. 3rd edn. Orlando, FL: Grune and Stratton, Inc, 1984:55-6.

23 Blackburn A, Doe W, Buffinton G. Salicylate hydroxylation as an indicator of hydroxyl radical generation in dextran sulfate-induced colitis. Free Radic Biol Med 1998;25:30513.

24 Wozniak A, Sharma DP, van de Pol E, et al. Depletion of neutrophils decreases disease severity and mortalitiy in a mouse model of colitis. [Abstract] Gastroenterology 1995; 108 (suppl):A944.

25 Sartor RB. Cytokines in intestinal inflammation: pathophysiological and clinical considerations. Gastroenterology 1994;106:533-9.

26 Grimm MC, Elsbury SK, Pavli P, et al. Interleukin 8: cells of origin in inflammatory bowel disease. Gut 1996;38:90-8.

27 McKenzie SJ, Doe WF, Buffinton GD. Selective recovery of colon epithelial cell GAPDH following in vitro exposure to oxidants. [Abstract] Gastroenterology 1997;112 (suppl): A1038.

28 Grisham MB, Gaginella TS, von Ritter C, et al. Effects of neutrophil-derived oxidants on intestinal permeability, electrolyte transport, and epithelial cell viability. Inflammation 1990;14:531-42.

29 Yamada T, Volkmer C, Grisham MB. Antioxidant properties of 5-ASA: potential mechanism for its anti-inflammatory activity. Can f Gastroenterol 1990;4:295-302.

30 Grisham MB, Granger DN. 5-Aminosalicylic acid concentration in mucosal interstitium of cat small and large intestine. Dig Dis Sci 1989;34:573-8.

31 Jensen J, Cornett C, Olsen CE, et al. Identification of major degradation products of 5-aminosalicylic acid formed in aqueous solutions and in pharmaceuticals. Int $\mathcal{F}$ Pharm 1992;88:117-87.

32 Galaris D, Cadenas E, Hochstein P. Redox cycling of myoglobin and ascorbate: a potential protective mechanism gainst oxidative reperfusion injury in muscle. Arch Biochem Biophys 1989;273:497-504.

33 Galaris D, Cadenas E, Hochstein P. Glutathione-dependent reduction of peroxides during ferryl- and met-myoglobin interconversion: a potential protective mechanism in muscle. Free Radic Biol Med 1989;6:473-8.

34 Buffinton $\mathrm{G}$, Cadenas E. Reduction of ferrylmyoglobin to metmyoglobin by quinonoid compounds. Chem Biol Interact 1988;66:233-50.

35 Buffinton G, Mira D, Galaris D, et al. Reduction of ferryland metmyoglobin to ferrous myoglobin by menadioneglutathione conjugate. Spectrophotometric studies under aerobic and anaerobic conditions. Chem Biol Interact 1988; 66:205-22.

36 Grisham MB, MacDermott RP, Deitch EA. Oxidant defence mechanisms in the human colon. Inflammation 1990;14:669-80.

37 von Ritter C, Grisham MB, Granger DN. Sulfasalazine metabolites and dapsone attenuate formyl-methionylleucyl-phenylalanine-induced mucosal injury in rat ileum. Gastroenterology 1989;96:811-16.

38 Grisham MB, Miles AM. Effects of aminosalicylates and immunosuppressive agents on nitric oxide-dependent $\mathrm{N}$-nitrosation reactions. Biochem Pharmacol 1994;47:1897902 . 